\title{
Erythrocyte Membrane Proteins of Premature and Full-term Newborn Infants
}

\author{
DONALD L. SHAPIRO ${ }^{(13)}$ AND PATRICIA PASQUALINI \\ Division of Perinatal Medicine, Department of Pediatrics, Yale University School of Medicine, New Haven, \\ Connecticut, USA
}

\section{Summary}

Erythrocyte membrane proteins of premature and full-term infants were analyzed by polyacrylamide gel electrophoresis. There were no qualitative or gross quantitative differences in the pattern of membrane proteins from premature infants, fullterm infants, and adults.

\section{Speculation}

Erythrocyte membrane proteins are constant in character from 30 weeks of fetal gestation through adulthood.

Cell membrane proteins have been actively studied because they are considered to play a critical role in many cell processes such as transport, intercellular recognition and communication, and control of growth (1). The cell membrane of the human erythrocyte has been extensively studied because its apparent homogeneity and the relatively small number of major proteins associated with it have made it an attractive model for studies on the biochemistry of cell membranes. Procedures for preparation of membranes (2) and a nomenclature for the proteins based on their migration in polyacrylamide gel containing sodium dodecyl sulfate (SDS) are generally accepted (4).

The characteristics of human erythrocyte membrane proteins analyzed by polyacrylamide gel electrophoresis in SDS are very reproducible and do not vary among adults. When stained with Coomassie blue, approximately 10 protein bands are discernible, and these are designated numerically from the origin. When stained with periodic acid-Schiff-reagent, three bands which represent the major membrane glycoproteins are apparent.

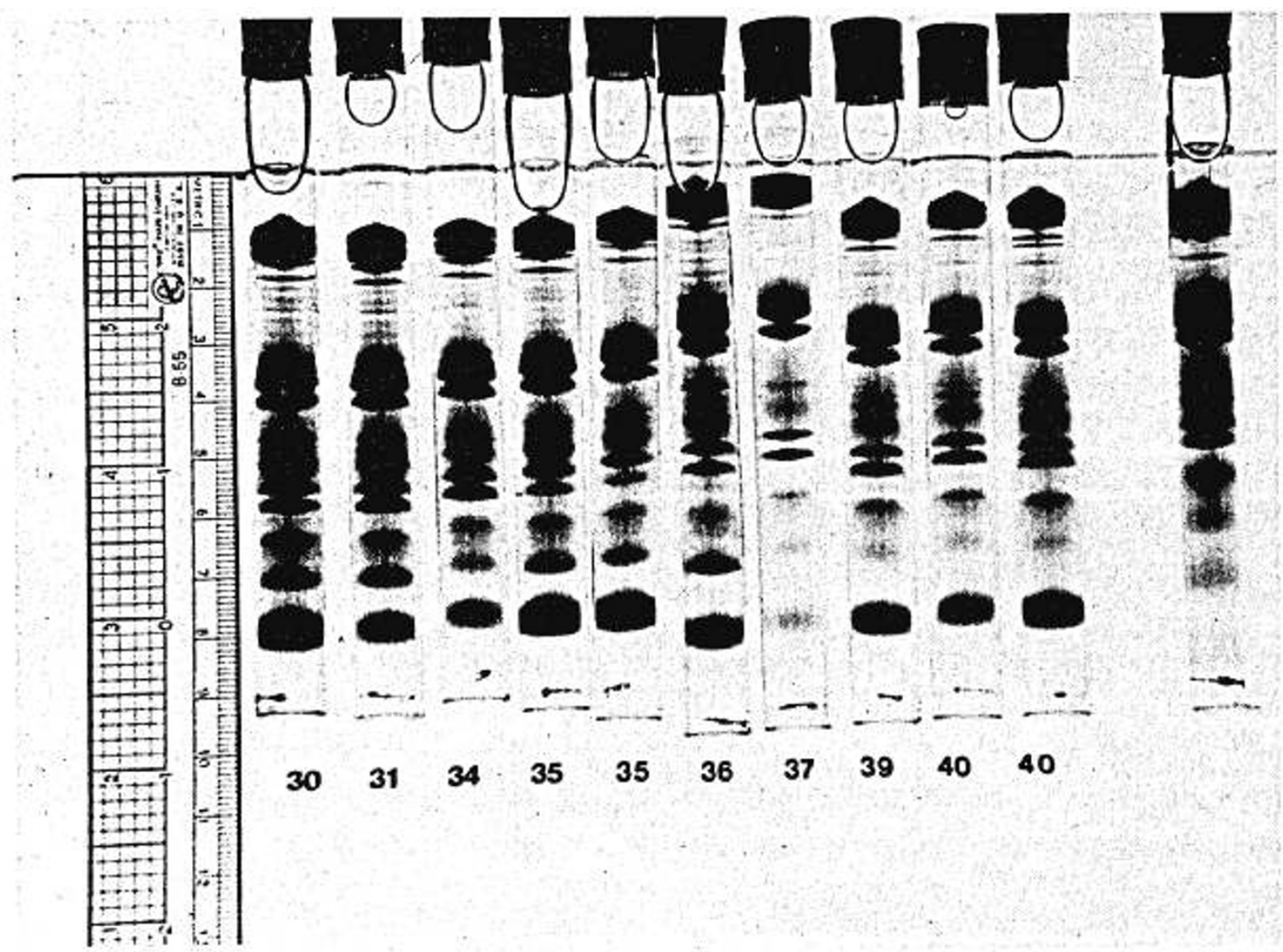

Fig. 1. The Coomassie blue stained gels from 10 infants and 1 adult. The gestational age of the infants in weeks is indicated under each gel. The only apparent difference is the hemoglobin content (the lowermost band on the gel). The smaller amount of material available from the infants did not allow as complete washing of the membranes, and therefore the residual hemoglobin of the preparation was greater. 
These are designated PAS-1, PAS-2, and PAS-3. Bands PAS- 1 and PAS-2 are interconvertible forms of the major human erythrocyte glycoprotein known as glycophorin (6). Glycophorin A (PAS-1) undergoes a molecular change with a resultant shift in its migration position (PAS-2) when it is heated to $100^{\circ}$ under appropriate conditions (6) prior to polyacrylamide gel electrophoretic analysis.

Although few differences exist between erythrocytes of older children and adults, there are significant differences in size, lipid content and composition (8), hemoglobin composition (5), and intracellular enzyme activities (9) between erythrocytes of newborn infants and those of adults. Therefore, it was of interest to determine whether significant differences existed between the membrane proteins of premature infants, full-term infants, and adults. Erythrocyte membranes from three full-term infants and seven premature infants were analysed for Coomassie blue staining pattern, periodic acid-Schiff staining pattern, and the shift of glycoprotein from band PAS-1 to PAS-2 with heating. For comparison, the same analyses were also performed on adult erythrocyte membranes.

\section{MATERIALS AND METHODS}

Cord blood samples were obtained from 10 newborn infants. Seven of the infants were premature with gestational ages of 3037 weeks. Three of the infants were full-term with gestational ages of 39-41 weeks. All of the infants were appropriate size for their gestational age and were born following uncomplicated pregnancies and deliveries. Gestational age was determined from maternal history and by the Dubowitz neurologic assessment (3). All infants had cord blood hematocrits within the normal range. Adult blood samples were obtained from healthy adult volunteers. Informed consent was obtained in all cases.

The blood samples were drawn into citrate preservative tubes, refrigerated at $4^{\circ}$, and all samples analyzed within 18 hours. The samples were centrifuged at $1000 \times \mathrm{g}, 4^{\circ}$, for $20 \mathrm{~min}$ and the serum and buffy coat were removed. Cells were washed four times in 5-10 vol cold isotonic phosphate buffered saline $(0.01$ $\mathrm{M}$ sodium phosphate, $\mathrm{pH} 7.42,0.15 \mathrm{M} \mathrm{NaCl}$ ). The visible buffy coat was removed after the first wash, and in subsequent washes the top layer of cells was discarded. Cell membranes (ghosts) were prepared from washed erythrocytes by repeated hypotonic lysis using the procedure described by Dodge (2). Sodium dodecyl sulfate-polyacrylamide gel electrophoresis was performed by the method of Fairbanks (4). Gels were stained with Coomassie blue or periodic acid-Schiff reagent (6). For studying the shift of PAS-1 to PAS-2, duplicate samples were heated to $100^{\circ}$ for $3 \mathrm{~min}$ and then cooled prior to gel analysis.

\section{RESULTS}

The results are shown pictorially in Figures 1 and 2. No differences were observed between the premature, full-term, and adult in the Coomassie blue staining pattern, the periodic acid-Schiff staining pattern, or in the shift of band PAS-1 to the PAS-2 position with heating.

\section{DISCUSSION}

The results indicated that while changes occur in intracellular protein content and composition during development from infancy to adulthood, the major membrane proteins are present as early as 30 weeks of gestation in approximately the same quantity as that of the adult erythrocyte. Some information is known about the function of some of the erythrocyte membrane proteins $(7,11)$. Bands I and II are the high molecular weight proteins known as spectrin which are thought to play a role, possibly in conjunction with the actin-like protein Band $\mathrm{V}$, in maintaining cell shape. Band III contains a number of proteins including a $\left(\mathrm{Na}^{+}-\mathrm{K}^{+}\right)$-ATPase, glycophorin $\mathrm{A}$, and one or more other proteins thought to be active in transport processes. Band VI is glyceraldehyde-3-phosphate dehydrogenase. It would seem

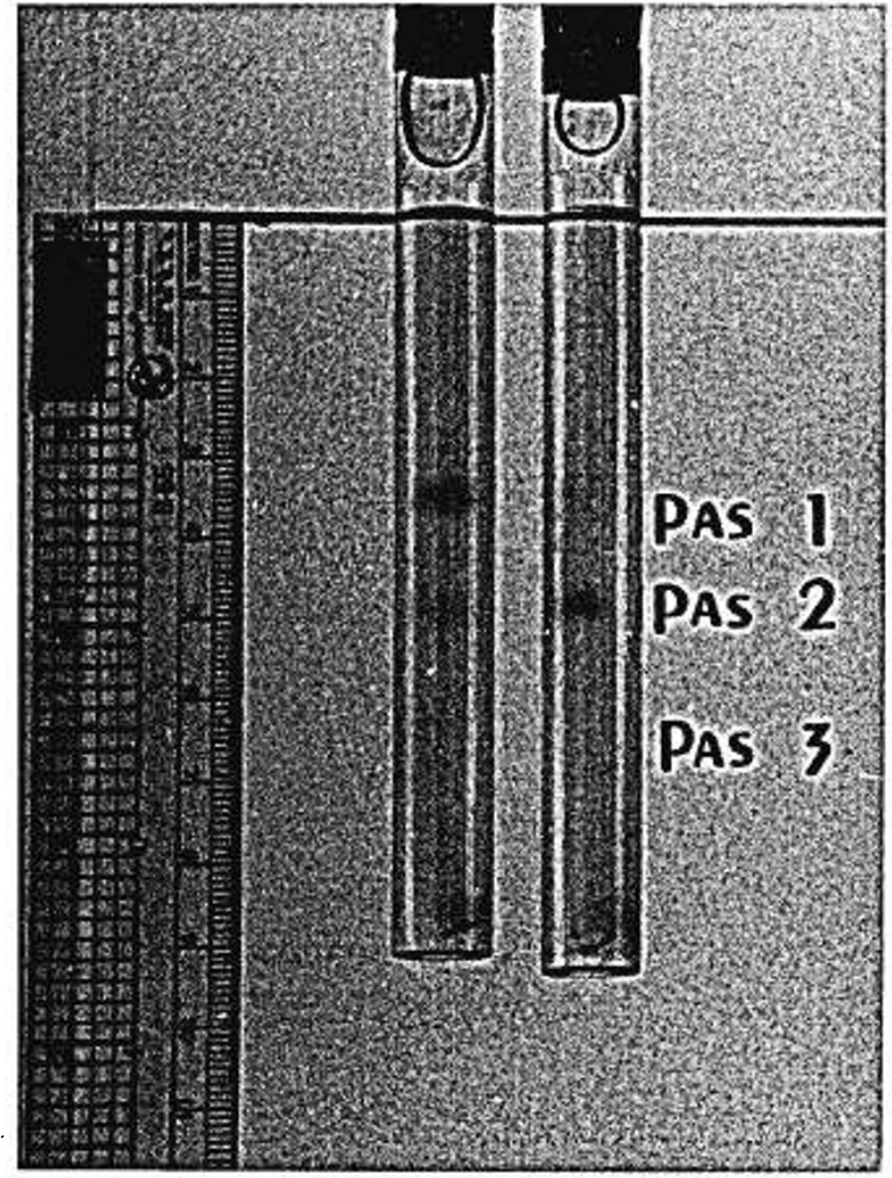

Fig. 2. Representative periodic acid-Schiff stained gels showing the glycoprotein pattern. Left: unheated; right: heated, showing the shift of material from the PAS-1 to the PAS-2 position. The gel shown is from a 30 weeks of gestation infant. All of the membranes analyzed exhibited the same pattern.

that whatever the function of the erythrocyte membrane proteins, a full complement is necessary to the human erythrocyte as early as 30 weeks of gestation. Their presence in adulthood implies that they are functional although there is no information to substantiate this.

The similarity in membrane proteins does not imply that there are no differences between the erythrocyte membranes of premature and full-term infants and adults. For example, it has been recently demonstrated that endocytosis of the plant lectin concanavilin $\mathrm{A}$ and the clustering phenomenon of concanavilin A membrane receptors is different in erythrocytes from newborn (presumably full-term) infants and adults (10). In that study the Coomassie blue protein patterns were also found to be similar, and the apparent functional differences were attributed to differences in membrane mobility and may be related to differences in membrane lipids.

\section{CONCLUSION}

Erythrocyte membrane proteins from premature infants, fullterm infants, and adults were analyzed by polyacrylamide gel electrophoresis. No differences were found in the staining or migration characteristics of the membrane proteins and glycoproteins.

\section{REFERENCES AND NOTES}

1. Chapman, D., and Wallach, D.: Biological Membranes, Vol. 2 (Academic Press, New York, 1973).

2. Dodge, J. T., Mitchell, C., and Hanahan, D. J.: The preparation and chemical characteristics of hemoglobin free ghosts of human erythrocytes. Arch. Biochem. Biophys., 100: 119 (1963). 
3. Dubowitz, L. M., Dubowitz, V., and Goldberg, C.: Clinical assessment of gestational age in the newborn infant. J. Pediat., 77: 1 (1970).

4. Fairbanks, G., Steck, T. L., and Wallach, D. F. H.: Electrophoretic analysis of the major polypeptides of the human erythrocyte membrane. Biochemistry, 10: 2606 (1971).

5. Finne, P. H., and Halvorsen, S.: Regulation of erythropoiesis in the fetus and newborn. Arch. Dis. Childhood, 47: 683 (1972).

6. Furthmayr, H., and Marchesi, V. T.: Subunit structure of human erythrocyte glycophorin A. Biochemistry, 15: 1137 (1976).

7. Marchesi, V. T., Furthmayr, H., and Tomita, M.: The red cell membrane. Ann. Rev. Biochem., 45: 667 (1976).

8. Neerhout, R. C.: Erythrocyte lipids in the neonate. Pediat. Res. 2: 172 (1968).
9. Oski, F. A.: Red cell metabolism in the newborn infant. V. Glycolytic intermediates and glycolytic enzymes. Pediatrics, 44: 84 (1969).

10. Schekman, R., and Singer, S. J.: Clustering and endocytosis of membrane receptors can be induced in mature erythrocytes of neonatal but not adult huinans. Proc. Nat. Acad. Sci. U.S.A., 73: 4075 (1976).

11. Steck, T. L., The organization of proteins in the human red blood cell membrane. J. Cell Biol., 62: 1 (1974).

12. This research was supported by a grant from the Charles H. Hood Foundation.

13. Requests for reprints should be addressed to: Dr. Donald L. Shapiro, Division of Perinatal Medicine, Department of Pediatrics, Yale University School of Medicine, 333 Cedar St., New Haven, CT 06510 (USA).

14. Received for publication March 7,1977.

15. Accepted for publication June 1, 1977.

0031-3998/78/1203-0176\$02.00/0

Copyright $\odot 1978$ International Pediatric Research Foundation, Inc.

Printed in U.S.A. 